Hydrology and Earth System Sciences, 9, 173-183, 2005

www.copernicus.org/EGU/hess/hess/9/173/

SRef-ID: 1607-7938/hess/2005-9-173

European Geosciences Union

\title{
Soil moisture-runoff relation at the catchment scale as observed with coarse resolution microwave remote sensing
}

\author{
K. Scipal ${ }^{1}$, C. Scheffler ${ }^{2}$, and W. Wagner ${ }^{1,3}$ \\ ${ }^{1}$ Vienna University of Technology Institute of Photogrammetry and Remote Sensing, Vienna, Austria \\ ${ }^{2}$ University of Jena, Institute of Geography, Jena, Germany \\ ${ }^{3}$ Christian Doppler Laboratory "Spatial Data from Laser Scanning and Remote Sensing”, Vienna, Austria
}

Received: 26 January 2005 - Published in Hydrology and Earth System Sciences Discussions: 2 March 2005

Revised: 29 June 2005 - Accepted: 2 August 2005 - Published: 16 August 2005

\begin{abstract}
Microwave remote sensing offers emerging capabilities to monitor global hydrological processes. Instruments like the two dedicated soil moisture missions SMOS and HYDROS or the Advanced Scatterometer onboard METOP will provide a flow of coarse resolution microwave data, suited for macro-scale applications. Only recently, the scatterometer onboard of the European Remote Sensing Satellite, which is the precursor instrument of the Advanced Scatterometer, has been used successfully to derive soil moisture information at global scale with a spatial resolution of $50 \mathrm{~km}$. Concepts of how to integrate macroscale soil moisture data in hydrologic models are however still vague. In fact, the coarse resolution of the data provided by microwave radiometers and scatterometers is often considered to impede hydrological applications. Nevertheless, even if most hydrologic models are run at much finer scales, radiometers and scatterometers allow monitoring of atmosphere-induced changes in regional soil moisture patterns. This may prove to be valuable information for modelling hydrological processes in large river basins $\left(>10000 \mathrm{~km}^{2}\right)$. In this paper, ERS scatterometer derived soil moisture products are compared to measured runoff of the Zambezi River in south-eastern Africa for several years (1992-2000). This comparison serves as one of the first demonstrations that there is hydrologic relevant information in coarse resolution satellite data. The observed high correlations between basin-averaged soil moisture and runoff time series $\left(R^{2}>0.85\right)$ demonstrate that the seasonal change from low runoff during the dry season to high runoff during the wet season is well captured by the ERS scatterometer. It can be expected that the high correlations are to a certain degree predetermined by the pronounced inter-annual cycle observed in the discharge behaviour of the Zambezi. To quantify this
\end{abstract}

Correspondence to: $\mathrm{K}$. Scipal

(kscipal@ipf.tuwien.ac.at) effect, time series of anomalies have been compared. This analysis showed that differences in runoff from year to year could, to some extent, be explained by soil moisture anomalies.

\section{Introduction}

Soil moisture is widely recognised as a key parameter in environmental processes, including meteorology, hydrology, agriculture and climate change. From a hydrologic viewpoint, soil moisture controls the partitioning of rainfall into runoff and infiltration and therefore has an important effect on the runoff behaviour of catchments (Aubert et al., 2003). An accurate assessment of the spatial and temporal variation of soil moisture may therefore be useful for improving the predictive capability of runoff models, and for improving and validating hydrologic process representations. Unfortunately, useful in-situ observations are rarely available as area representative measurements are expensive and tedious to collect (Hollinger and Isard, 1994; Rombach and Mauser, 1997). The difficulty of measuring soil moisture on the ground has motivated considerable research in the field of remote sensing (Engman and Chauhan, 1995). Specifically, microwave remote sensing offers the possibility to retrieve soil moisture information at various scales.

Much emphasise has been put on Synthetic Aperture Radars (SAR), the only system which can provide information on smaller scales $(<50 \mathrm{~m})$, with some success being achieved using change detection approaches (see e.g. Moran, 2000). However, currently available SAR systems neither provide the data necessary for routine application nor are they truly optimised for soil moisture retrieval. That is why SAR studies are in general still experimental and progress has been slower than expected. At the same time,

(C) 2005 Author(s). This work is licensed under a Creative Commons License. 
significant progress has been made using coarse-resolution microwave radiometers and scatterometers. The advantage of these systems compared to SAR is that they offer multidimensional, multi-temporal observation capabilities (multiple frequencies and polarisations in the case of microwave radiometers and multiple-viewing capabilities in the case of scatterometers). These capabilities allow one to better account for the confounding effects of vegetation and surface roughness, which are inherent in both active and passive microwave observations. The progress made, led to the approval of two experimental satellite missions optimised to measure soil moisture, ESA's Soil Moisture and Ocean Salinity Mission (SMOS) and NASA's Hydrosphere Sate Mission (HYDROS). As low microwave frequencies are beneficial for soil moisture retrieval (longer wavelengths better penetrate vegetation) both missions will be operated in L-band. SMOS will use a radiometer to make measurements at a spatial resolution of about $40 \mathrm{~km}$ (Kerr et al., 2001). HYDROS will combine a radiometer $(40 \mathrm{~km})$ and a scatterometer $(3$ and $10 \mathrm{~km}$ ). Foreseen launch dates are 2007 and 2010, respectively. These two missions will perform first-of-a-kind exploratory measurements and aim to measure soil moisture with an accuracy of $0.04 \mathrm{~m}^{3} \mathrm{~m}^{-3}$.

Beside these dedicated hydrological missions, operational satellite missions not optimised for soil moisture retrieval have also been found useful. Attention has been put on the Advanced Microwave Scanning Radiometer (AMSR) on the Aqua satellite and the scatterometers on the European Remote Sensing satellites (ERS). Only recently a global surface soil moisture product based on AMSR data has been published (Njoku, 2004). The novelty of the data set and the still limited temporal availability of data however constrain scientific applications. Data from the ERS scatterometer have been used for the first time to derive a global validated long term soil moisture dataset (Scipal, 2002; Scipal et al., 2002). The data set has a spatial resolution of $50 \mathrm{~km}$ and a comparable quality with state-of-the-art, global soil moisture models (Wagner et al., 2003). The accuracy of the scatterometer based soil moisture product was assessed using over 45000 measurements worldwide and is around $0.054 \mathrm{~m}^{3} \mathrm{~m}^{-3}$ for the $0-1 \mathrm{~m}$ layer for temperate and tropical climatic regions (a red-noise filtering approach was used to estimate the water content in the soil profile from the remotely sensed surface soil moisture series). The retrieval algorithm developed for the ERS scatterometer will be directly applicable to its successor, the Advanced Scatterometer (ASCAT). This instrument has a spatial resolution of $25 \mathrm{~km}$ and will be flown on a series of METOP satellites, providing data continuity over an initial period of at least 14 years, starting in 2006.

The coarse resolution of these sensors is however often assumed to be insufficient for hydrologic applications, therefore they have so far not been considered by the hydrologic community. Given the impending launch of a series of coarse resolution microwave sensors capable of retrieving soil moisture and the unavailability of other data sources, the logic dictates, that it is necessary to investigate the potential of these techniques to support hydrologic applications. Clearly, substantial research efforts will be needed to develop methods for ingesting data into hydrologic models. The questions of spatial resolution, irregular sampling intervals, and low penetration depth into the soil surface need to be addressed. Fortunately, the technique of data assimilation has recently gained significant attention and will provide important impetus in the future (e.g. Walker et al., 2001).

Before complex hydrological assimilation schemes are developed, it is advisable to gain a better understanding of the available information. This is the aim of this paper, which compares ERS scatterometer soil moisture with runoff time series from the Zambezi River. The Zambezi River has been chosen for this investigation because of its large catchment area and its pronounced intra- and inter-annual variability in runoff. Before the results of this comparison are presented in Sect. 7, Sect. 2 reviews a number of studies, which investigated the possibility of using soil moisture observations for improving runoff prediction. Soil moisture scaling issues are addressed in Sect. 3 to lay the foundation for assessing the information contained in coarse resolution data. The soil moisture retrieval technique based on ERS scatterometer data is explained in Sect. 4, including a more detailed discussion on the accuracy of the derived soil moisture products in Sect. 5. The available hydrometric data are described in Sect. 6. The discussion of the results aims particularly at identifying the information inherent in the macro-scale soil moisture products.

\section{State of the art}

In recent years there have been a few studies geared towards combining hydrologic models and space borne data to improve runoff models, or just to use the data to improve and validate hydrologic process representation at catchment scale.

Classically, soil moisture observations are not used directly to address hydrologic problems such as runoff prediction, drought monitoring or flood forecasting, but are used in assimilation schemes of land surface hydrologic models or to constrain soil vegetation atmosphere transfer models (Aubert et al., 2003; for examples see Houser et al., 1998; Li and Islam, 1999; Walker et al., 2001; Walker and Houser, 2001; Reichle et al., 2001). Most of these studies focused on the assimilation technique itself and its influence on the soil water content, but did not examine the effect of the soil moisture assimilation on other modelled fluxes such as discharge and evapotranspiration (Pauwels et al., 2001). This was also noted by Aubert (2003) who states that coupling soil moisture observations with the routing function of hydrological models, in order to improve stream flow simulations and forecasts, has not extensively been studied. However, first experimental studies confirm that assimilation of remotely 
sensed soil moisture can significantly improve simulation results especially under extreme conditions.

Pauwels (2001) examined the effect of ERS SAR derived soil moisture assimilation on modelled discharge, concluding that the data assimilation could improve model based discharge estimates. In the study, a lumped hydrologic model was used in combination with two assimilation methods of remotely sensed soil moisture. One assimilation method used the spatial patterns, the other only the spatial mean and variance of observed soil moisture. Assimilation of the spatial mean and variance already improved hydrological model based discharge predictions. These results suggest that the mean value captured by coarse resolution soil moisture is a statistically meaningful descriptor, which may help to improve simulation results regardless of scale differences between model and data.

Francois et al. (2003) and Bach and Mauser (2003) showed that spaceborne observations of soil moisture are especially useful to improve simulation results under extreme flood conditions. Francois et al. (2003) used an extended Kalman filter with a lumped rainfall runoff model, Bach and Mauser (2003) a four dimensional data assimilation method with a flood forecasting model. Similar results were obtained by Aubert et al. (2003) showing that observed soil moisture can be used to improve runoff prediction over a sub-catchment of the Seine River in France. Although not using remotely sensed data, the study elaborates on the use of remotely sensed soil moisture observations and indicates its potential if provided frequently enough (1-3 days). This high temporal sampling requirements can currently only be fulfilled by coarse resolution sensors. Although none of these studies directly used coarse resolution data, they indicate the potential of coarse resolution data and point to possible ways forward in the use of macro scale soil moisture products.

\section{Soil moisture scales}

To make best use of a certain data set it is essential to define the processes captured by the data set, to understand the processes influencing the observed quantity, the scale at which the variability acts and finally the relation between the process and the observation scale. According to Grayson et al. (2002), scale is one of the key issues in hydrologic applications. It is not only a question of how to observe relevant features but also to observe and use them at the appropriate scale. In the ideal case process scale, model scale and the measurement scale are compatible (Blöschl, 1996). The process scale characterizes the typical time and length scales on which the process takes place, while the measurement scale refers to the spatial resolution and temporal sampling interval of the measurement device.

Based on in-situ soil moisture data, scaling properties of the soil moisture field have been investigated. It has been found that soil moisture is spatially and temporally highly variable. Several authors showed that the variability is driven by vegetation, soil type and topography and suggested that the spatial scale of soil moisture is on the order of tens of meters (Nielsen et al., 1973; Vieira et al., 1981; Vachaud et al., 1985). The perception was, that beyond this distance there is too much variability of soil, vegetation and topography to maintain a correlation of soil moisture. Concurrently it was argued by Kontorschikov (1979), Meshcherskaya et al. (1982) and more recently by Cayan and Georgakakos (1995) that a second factor influences soil moisture variability on a scale of hundreds of kilometres and attributed it to atmospheric forcing effects. Studies by Vinnikov et al. (1996) and Entin et al. (2000) support the two scale concept with a small scale component influenced by vegetation, soil type and topography acting on the range of centimetres to hundreds of meters and a large scale component influenced by climatic conditions and atmospheric events such as precipitation and radiation acting on scales of kilometres and larger. Vinnikov et al. (1999) argued that small scale variability does not effect soil moisture above $1 \mathrm{~km}$, and that above this scale the variability in soil moisture for the scale of typical coarse resolution sensors (ranging from $1 \mathrm{~km}$ to $100 \mathrm{~km}$ resolution) is relatively constant.

Evidence of a two scale concept are also found in Ceballos et al. (2002) and Martínez-Fernández and Ceballos (2003). The authors studied characteristics of soil moisture in a semiarid environment based on data from the REMEDHUS network located in the North West of the Iberian Peninsula. The network consists of twenty soil moisture measurement stations spread over a $1200 \mathrm{~km}^{2}$ large area, characterised by different soil and land use types. The stations are within the same climatological context but are hydrologically independent. The analysis of multi-year soil moisture time series indicated clear spatial patterns of persistence. Some stations were noted to be consistently wetter than the average while some were consistently drier, independent of the point in time. Still, all stations followed the same temporal trend and a high correlation between the twenty stations could be observed. Differences in absolute soil moisture were explained by differences in soil type, texture and topography.

This leads to the conclusion that observations made with coarse resolution sensors, which effectively average over the small-scale structure of the observed region, contain information about the large-scale component which refers to meteorological and climatic events.

\section{Soil moisture from scatterometer data}

Soil moisture data used in this study are taken from the Global Soil Moisture Archive 1992-2000 located at http:// www.ipf.tuwien.ac.at/radar/ers-scat/home.htm (Scipal et al., 2002). The archive is based on ERS Scatterometer data and comprises global surface soil moisture data and indicators of root zone soil moisture sampled at ten-day intervals. 
Scatterometers are active microwave sensors with a coarse spatial and a high temporal resolution. To retrieve soil moisture information, scatterometers onboard of the European Remote Sensing Satellites ERS-1 and ERS-2 were used. The ERS scatterometer operates at $5.3 \mathrm{GHz}$ (C-band) vertical polarization, collecting backscatter measurements over an incidence angle range from $18^{\circ}$ to $57^{\circ}$ using three sideways looking antennae. The sensor achieves global coverage within 3 to 4 days where each beam provides measurements of radar backscatter for overlapping $50 \mathrm{~km}$ resolution cells with a $25 \mathrm{~km}$ grid spacing at approximately 10:30 a.m. and 10:30 p.m. for ascending and descending tracks, respectively.

Scatterometry offers capabilities to infer soil moisture due to the strong variation of the dielectric constant of soil with volumetric water content. However, scattering from land surfaces also depends on other factors. Potential retrieval techniques must account for the confounding effects of surface roughness, vegetation, topography and soil texture. Since the 1970's several methods have been developed to retrieve soil moisture from microwave remote sensing data. Possibly the largest potential is held by change detection approaches. Change detection has successfully been used to retrieve soil moisture for active (Wagner et al., 1999c; Moran et al., 2000) and passive data (deRidder, 2000). Unlike more complex theoretical or semi empirical approaches often preferred for retrieval purposes, change detection is attractive for global applications because comprehensive pre-knowledge of surface characteristics is not required.

Retrieval of soil moisture for "The Global Soil Moisture Archive" is based on the change detection method developed by Wagner et al. (1999c). The method fully accounts for the effects of surface roughness, vegetation and heterogeneous land cover (Wagner et al., 1999a, b, c). It allows the retrieval of surface soil moisture information equivalent to the degree of saturation in relative units (ranging between 0 and $100 \%$ ). To infer root zone soil moisture a red-noise filtering approach was used, which is controlled by the ratio of the layer depth and the pseudo diffusivity that depends on soil properties (Wagner et al., 1999c; Ceballos et al., 2005). As soil properties are not known quantitatively on a global scale, this parameter was determined empirically and set constant (Wagner et al., 1999c). The resulting index is the Soil Water Index $S W I$, a percentile measure of soil moisture between the soil moisture extremes $\Theta_{\min }$ (dry) and $\Theta_{\max }$ (wet) which have been shown to correlate well with the wilting level and the point central to the field-capacity and the total water capacity (Wagner et al., 1999c).

\section{Soil moisture quality}

To assess the quality of scatterometer derived soil moisture, data from "The Global Soil Moisture Archive 1992-2000" has been compared extensively with soil moisture information from various sources.

Wagner et al. (2003) compared scatterometer derived soil moisture with gridded precipitation data and modelled soil moisture. The study showed that there is reasonable agreement between the different datasets especially in tropical and temperate climates. Only in extreme climates such as deserts and the arctic, spurious effects have been observed. Given, that the accuracy of the gridded precipitation and the modelled soil moisture is not known it is not possible to draw any quantitative conclusions. Considering that the datasets are independent it is however reasonable to assume that a high agreement indicate regions of good data quality and that in such a case upper limits of the accuracy of the scatterometer derived soil moisture can be inferred. This upper limit has been determined to be in the range of $0.03-0.07 \mathrm{~m}^{3} \mathrm{~m}^{-3}$.

A quantitative assessment of the soil moisture product was carried out by Scipal (2002) using over 45000 soil moisture measurements from 372 stations worldwide. Samples were taken at agro-meteorological networks covering a wide range of soil types and climatic regions located in Russia, Ukraine, China, Mongolia and the US. For Ukraine, Russia and Illinois soil moisture samples from a depth of $1 \mathrm{~m}$ were compared. In India and China, soil moisture samples from a depth of 50 and $60 \mathrm{~cm}$ were used. Statistical analysis showed an accuracy of $0.049 \mathrm{~m}^{3} \mathrm{~m}^{-3}$ and $0.084 \mathrm{~m}^{3} \mathrm{~m}^{-3}$ depending on the measurement network. The average accuracy was $0.054 \mathrm{~m}^{3} \mathrm{~m}^{-3}$. Even better values have been determined for soil moisture anomalies with an average accuracy of $0.032 \mathrm{~m}^{3} \mathrm{~m}^{-3}$.

A more detailed study, was carried out by Ceballos et al. (2005) who compared scatterometer derived soil moisture to field observations from the REMEDHUS network. All stations of the REMEDHUS network are within one scatterometer pixel therefore allowing a more detailed assessment of soil moisture conditions. For the comparison, data from twenty stations were averaged. The resulting time series compared well with scatterometer derived soil moisture. The coefficient of determination $R^{2}$ for the average soil moisture profile $(0-100 \mathrm{~cm})$ reached a value of 0.74 and the mean square error (RMS error) was $0.022 \mathrm{~m}^{3} \mathrm{~m}^{-3}$.

\section{Hydrometric data}

Hydrometric data is available for the Zambezi River. The basin of the Zambezi River is one of the largest of the African continent covering approximately 1.35 million $\mathrm{km}^{2}$ or $5 \%$ of the continent. The Zambezi River runs through six countries: Zambia, Angola, Zimbabwe, Namibia, Botswana and Mozambique, from the centre of Africa to the Indian Ocean. The source of the Zambezi River is situated at Kalenehills in the northwestern part of Zambia. At the frontier to Zimbabwe, the Zambezi reaches a width of $1.7 \mathrm{~km}$ before it reaches the Victoria falls. The entire river length is $3000 \mathrm{~km}$ 
Table 1. Gauging stations on the Zambezi River used in this study.

\begin{tabular}{lcrcc}
\hline Gauging station & River & Location & Catchment size & Measurement \\
\hline Kalabo & Luanginga & $14^{\circ} 58^{\prime} \mathrm{S}-22^{\circ} 41^{\prime} \mathrm{E}$ & $28500 \mathrm{~km}^{2}$ & Discharge \\
Watopa Pontoon & Kabompo & $14^{\circ} 02^{\prime} \mathrm{S}-23^{\circ} 37^{\prime} 30^{\prime \prime} \mathrm{E}$ & $66750 \mathrm{~km}^{2}$ & Discharge \\
Chavuma Mission & Zambezi & $13^{\circ} 05^{\prime} \mathrm{S}-22^{\circ} 41^{\prime} \mathrm{E}$ & $76000 \mathrm{~km}^{2}$ & Discharge \\
Victoria Falls & Zambezi & $17^{\circ} 55^{\prime} \mathrm{S}-25^{\circ} 50^{\prime} \mathrm{E}$ & $507200 \mathrm{~km}^{2}$ & Discharge \\
Nanas Farm & Zambezi & $17^{\circ} 50^{\prime} \mathrm{S}-25^{\circ} 39^{\prime} \mathrm{E}$ & $524000 \mathrm{~km}^{2}$ & Discharge \\
Lukulu & Zambezi & $14^{\circ} 23^{\prime} \mathrm{S}-23^{\circ} 14^{\prime} \mathrm{E}$ & $212450 \mathrm{~km}^{2}$ & Water level \\
Matongo & Zambezi & $15^{\circ} 16^{\prime} \mathrm{S}-23^{\circ} 03^{\prime} 30^{\prime \prime} \mathrm{E}$ & $245000 \mathrm{~km}^{2}$ & Water level \\
Senanga & Zambezi & $16^{\circ} 07^{\prime} \mathrm{S}-23^{\circ} 23^{\prime} 15^{\prime \prime} \mathrm{E}$ & $290572 \mathrm{~km}^{2}$ & Water level \\
Sesheke & Zambezi & $17^{\circ} 25^{\prime} \mathrm{S}-20^{\circ} 12^{\prime} \mathrm{E}$ & $322500 \mathrm{~km}^{2}$ & Water level \\
\hline
\end{tabular}

from source to estuary (Zambezi River Authority, 2002). Along the Zambezi River two major dams (Lake Kariba and Cabora Bassa) have been built that are mainly used for generation of energy.

The climate of the Zambezi catchment underlies the movement of the Intertropical Convergence zone ITC, resulting in distinct dry and wet seasons during the year. Consequently, the flow of the Zambezi River is seasonal with the lowest flows occurring from June to November and the higher flows occurring from December to May. The study period, was characterized by a wet period from 1992 to 1994, followed by a rather dry period from 1995 to September 1997. The end of the study period was characterized by extreme wet conditions with disastrous floods in the years 1997 and 2000.

The Zambezi River Authority in Zambia provided daily water level data from eleven stations (Fig. 1). At seven of these stations, additional flow measurements are carried out which allows calculation of runoff. Records of the stations Gwayi and Sanyati are incomplete and have therefore not been used in this study. The observations cover the years 1992 to 2000. Only stations above Lake Kariba have been used, which are Chavuma, Watopa, Lukulu, Kalabo, Matongo, Senanga, Sesheke, Nana's Farm and Victoria Falls (Table 1). For the station Sesheke unrealistic low water level values have been recorded for the period March 1997 to October 1998 which do not fit with the other measurements. These records have been removed.

\section{Results}

Studying the relationship between soil moisture and hydrometric parameters is not straightforward. Principally it can be expected that both parameters are related. When soils are close to saturation runoff will be much higher compared to the situation when soils are dry. However given the different nature of the parameters it can be expected that no linear relationship exists but that a more complex interaction between the processes has to be considered. Soil moisture will, for

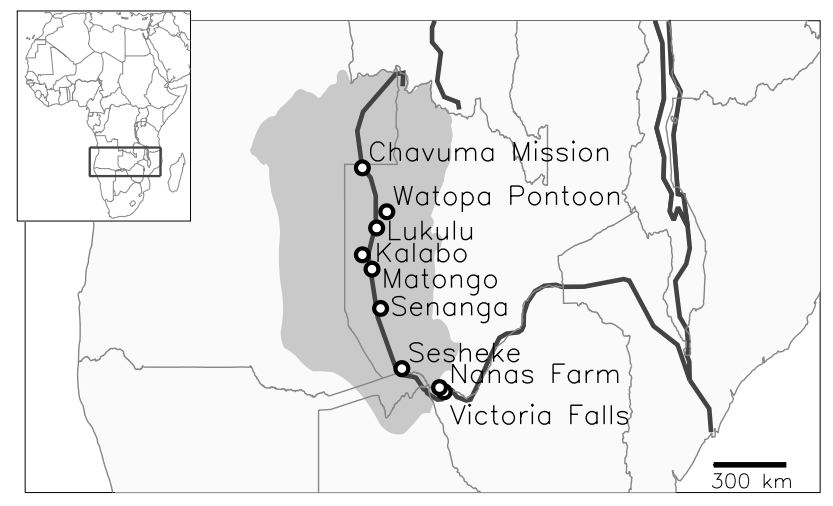

Fig. 1. The catchment of the Zambezi River with the location of the nine gauging stations used in this study.

example, show higher sensitivity to changes under dry conditions compared to runoff. Under prolonged wet conditions soil moisture will saturate and will be insensitive to additional rainfall. Runoff, conversely, is theoretically not bound to an upper limit and will be highest under such conditions. Additionally, it has to be considered that runoff is a point measurement integrating information on the hydrologic status of an entire catchment. To get a representative indicator, SWI data has therefore been integrated over all grid points of the sub basins according to Eq. (1) to derive a "Basin Water Index" $B W I$ :

$B W I=\frac{\sum_{i=1}^{N} S W I_{i}}{N}$.

In this simplistic approach the position of each sample point with respect to the hydrometric gauging station is not considered. It can be expected that each point shows a unique relation to the gauging station which is determined by the geomorphology of the basin. This will specifically be the case for large catchments. Equation (1) also assumes that all points in the catchment are equally relevant for the 


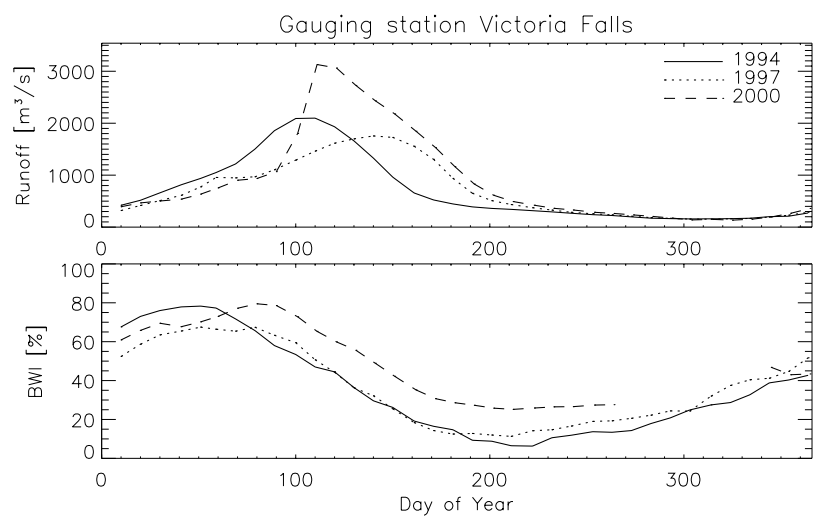

Fig. 2. Runoff and Basin Water Index series for the station Victoria Falls situated on the Zambezi River for the years 1994, 1997 and 2000.

generation of runoff. For the sake of simplicity of this explanatory analysis more realistic schemes were set aside. To retrieve temporal matching data sets daily hydrometric parameters have been averaged over ten day periods.

The first step in the analysis was to visually compare the scatterometer derived soil moisture with samples from hydrometric gauging stations. It was examined if similar temporal trends can be observed in both datasets. Figure 2 shows discharge and $B W I$ time series for the station Victoria Falls for the years 1994, 1997 and 2000. The year 1994 is characteristic for wet conditions, the year 1997 for dry conditions whereas the year 2000 was an extreme wet year with disastrous floods. These climatic differences are well reflected in both time series. However, the extreme conditions of the year 2000 are better visible in the discharge time series than in the $B W I$ time series. Generally, it can be observed that the $B W I$ shows less variability between the sampled years than the hydrometric data. However, annual variations in the $B W I$ are clearly evident for all stations. In Fig. 2 it can also be observed that the maximum runoff lags some time behind the maximum $B W I$. For the station Victoria Falls the highest runoff is recorded between April and May, whereas the $B W I$ maximum is observed between February and March. The time difference in the observed maxima is most likely explained with the delay time of the discharge system. It can be expected that runoff measured at a gauging station shows a much slower response to precipitation events than soil moisture which will immediately respond. This is also in agreement with the observation that the magnitude of the delay time increases with the basin size. Despite this difference in the two data sets, differences in the annual cycle are clearly visible and follow the climatic conditions experience during the study period.

In the second step of the analysis, the relation between the hydrometric parameters and the $B W I$ has been assessed quantitatively. For this purpose hydrometric samples have been plotted against the $B W I$ for all stations. To account for
Table 2. Parameters of the logarithmic model given in Eq. (2) after optimising the fit between the model and the parameters for all stations, and coefficients of correlation $R$ for the whole year and for the wet and dry seasons.

\begin{tabular}{lccccccc}
\hline Gauging station & $Q_{0}$ & $\chi_{Q}$ & $B W I_{\max }$ & $\Delta_{t}$ & $R$ & $R_{\text {Dry }}$ & $R_{\text {Wet }}$ \\
\hline Watopa Pontoon & 32.78 & 93.08 & 82.4 & 30 & 0.94 & 0.83 & 0.96 \\
Chavuma Mission & 8.55 & 151.28 & 75.1 & 40 & 0.96 & 0.97 & 0.94 \\
Victoria Falls & 19.87 & 711.63 & 74.7 & 60 & 0.95 & 0.63 & 0.92 \\
Nana's Farm & 56.69 & 630.29 & 73.3 & 60 & 0.96 & 0.48 & 0.93 \\
\hline
\end{tabular}

Table 3. Parameters of the logarithmic model given in Eq. (3) after optimising the fit between the model and the parameters for all stations, and coefficient of correlation $R$ for the whole year and for the wet and dry seasons.

\begin{tabular}{lccccccc}
\hline Gauging station & $h_{0}$ & $\chi_{h}$ & $B W I_{\max }$ & $\Delta_{t}$ & $R$ & $R_{\text {Dry }}$ & $R_{\text {Wet }}$ \\
\hline Lukulu & 1.52 & 0.88 & 82.6 & 30 & 0.92 & 0.79 & 0.95 \\
Matongo & 1.48 & 1.93 & 84.1 & 50 & 0.96 & 0.82 & 0.95 \\
Senanga & 0.15 & 1.67 & 83.6 & 60 & 0.96 & 0.93 & 0.90 \\
Sesheke & 4.77 & 1.52 & 78.9 & 60 & 0.96 & 0.84 & 0.93 \\
\hline
\end{tabular}

the response time observed in the time series, hydrometric data was shifted back such that the observed maxima corresponded. To achieve correspondence between the maxima, different time shifts had to be applied to each individual station. Figures 3 and 4 show the plots of the $B W I$ and the shifted runoff and water level data. The best fit and hence the magnitude of the applied shift was determined using a simple regression model. The models used to determine the relation between the $B W I$ and the hydrometric parameters (runoff and water level) has been set up empirically. The regression models are given in Eqs. (2) and (3) where the first is used for discharge measurements and the second is used for water level measurements. Although both models are mathematically identical they have been defined separately to allow a correct interpretation of the parameters. In Eq. (2) the discharge $Q$ at time $t$ is determined by the "baseflow" $Q_{0}$, the highest observed Basin Water Index $B W I_{\max }$, a hydrometric scaling factor $\chi_{Q}$ and the delay time $\Delta t$ :

$Q(t)=Q_{0}+\chi_{Q} \ln \frac{B W I_{\max }}{B W I_{\max }-B W I(t-\Delta t)}$.

Similarly, in Eq. (3) the water level $h$ at time $t$ is determined by the lowest water level $h_{0}$, by the highest observed Basin Water Index $B W I_{\max }$, a hydrometric scaling factor $\chi_{h}$ and the delay time $\Delta t$ :

$h(t)=h_{0}+\chi_{h} \ln \frac{B W I_{\max }}{B W I_{\max }-B W I(t-\Delta t)}$.

The models were defined in a way that their parameters can be related to physical quantities. The baseflow $Q_{0}$ and the 

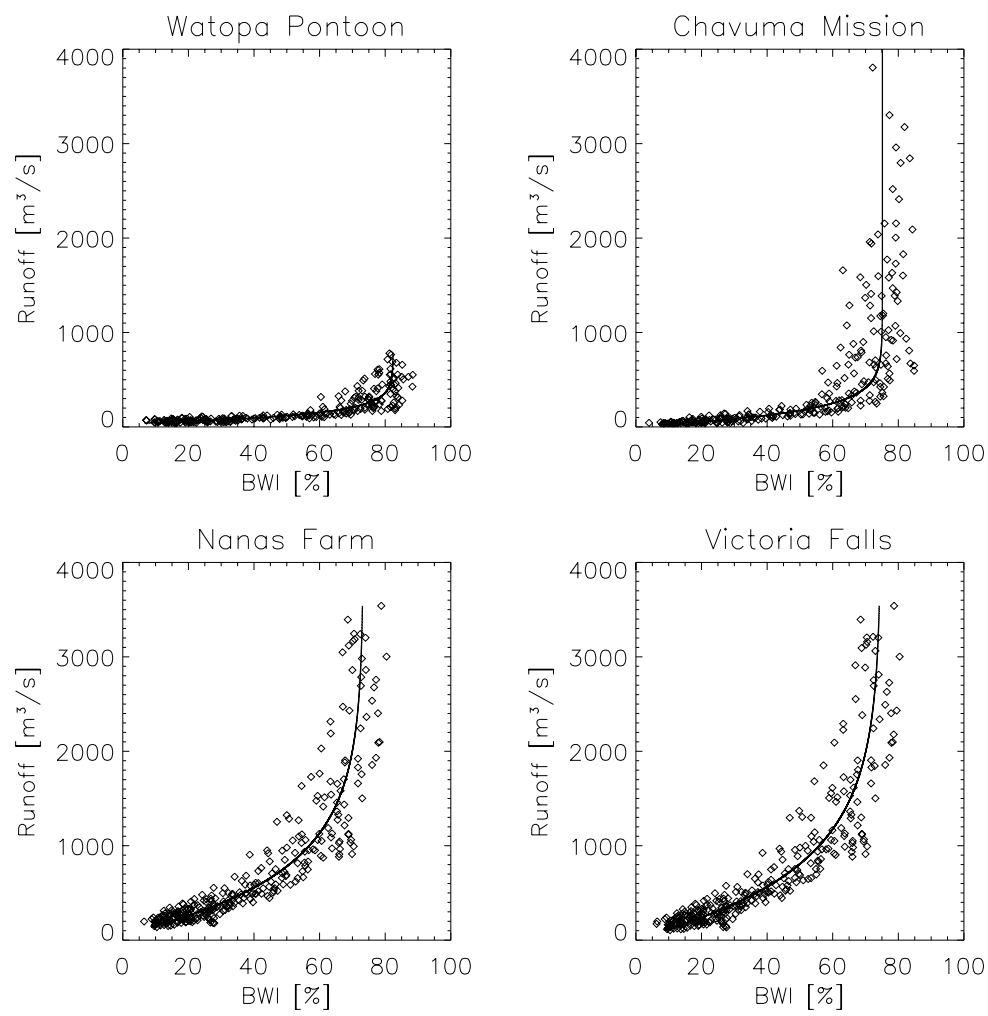

Fig. 3. Scatterplot of Basin Water Index and runoff at four gauging stations of the Zambezi River. Runoff data has been shifted back such that the observed maxima corresponded. The fitted model of Eq. (2) is also shown.
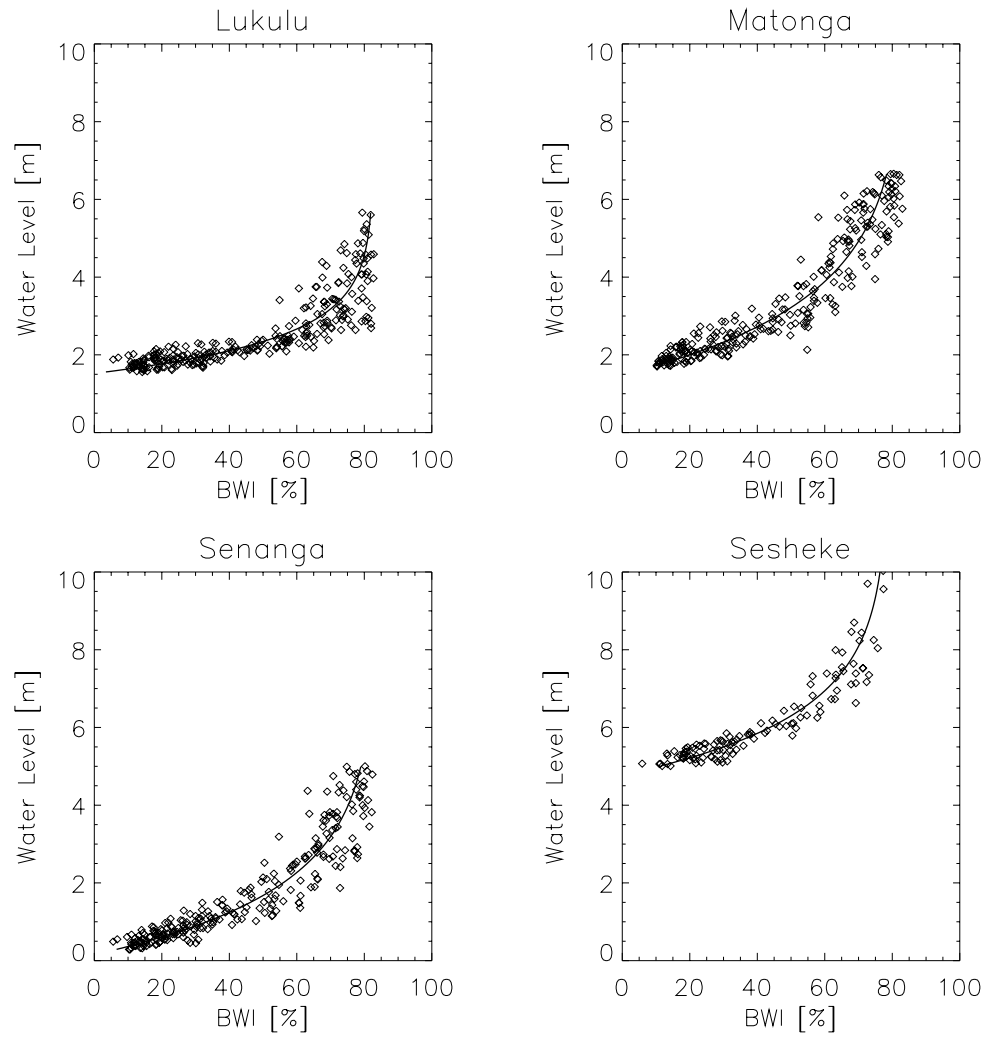

Fig. 4. Scatterplot of Basin Water Index and water level at four gauging stations of the Zambezi River. Water level data has been shifted back such that the observed maxima corresponded. The fitted model of Eq. (3) is also shown. 


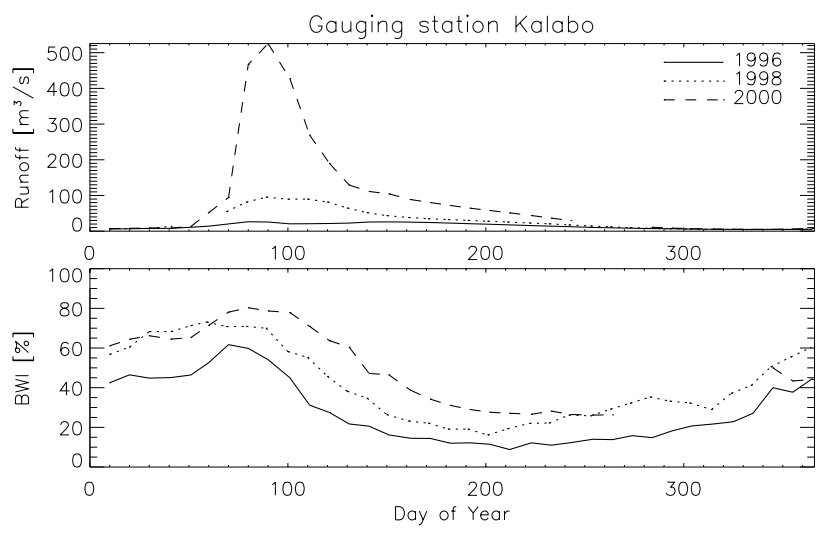

Fig. 5. Runoff and Basin Water Index series for the station Kalabo situated at the Luanginga River for the years 1996, 1998 and 2000.

water level $h_{0}$ relate to the waterflow when soils are completely dry. The highest observed $B W I$ relates to the threshold where the soils are close to saturation and any additional rainfall will directly result in runoff. The hydrometric scaling factor is necessary to determine the shape of the logarithmic model, such influencing the soil moisture runoff/water level behaviour. The delay time $\Delta t$ determines the difference observed in the temporal response of the two parameters to precipitation events.

The fit of the regression model expressed in Eqs. (2) and (3) is excellent as can be observed in Figs. 3 and 4. Only for the station Kalabo the fitting procedure of the model did not converge. The reason for this is the extreme temporal pattern observed at the Kalabo station with very low runoff during the entire observation period and one exceptional high runoff event in 2000, which significantly exceeded samples taken at previous years (Fig. 5). The logarithmic model, described in Eq. (2), is from a mathematical point of view, not suited to describe such extreme behaviour. For all other stations the estimated coefficients of determination are well above $R^{2}=0.8$ for all stations (Tables 2 and 3). Evidentially, the parameters $Q_{0}, h_{0}$ and $B W I_{\max }$ also give realistic numbers. It is interesting to note that the delay time $\Delta t$ shows a dependency on the catchment size. For upstream gauging stations a delay time of 30 days is estimated, for downstream stations this value increases to 60 days (Fig. 6). Also the hydrometric scaling factor increases with basin size. Obviously the parameters $Q_{0}, h_{0}, \Delta t$ and $B W I_{\max }$ depend on the geomorphology of the Zambezi basin. From a hydrologists point of view this might lead to new insight in the soil moisture runoff behaviour. Quantitative information about the basin and its structure is unfortunately not publicly available. A meaningful analysis was therefore not possible.

Although the results are favourable they need to be considered carefully. It can be expected that the pronounced inter-annual cycle observed in the discharge behaviour of the Zambezi with a very dry period and a wet period predeter-

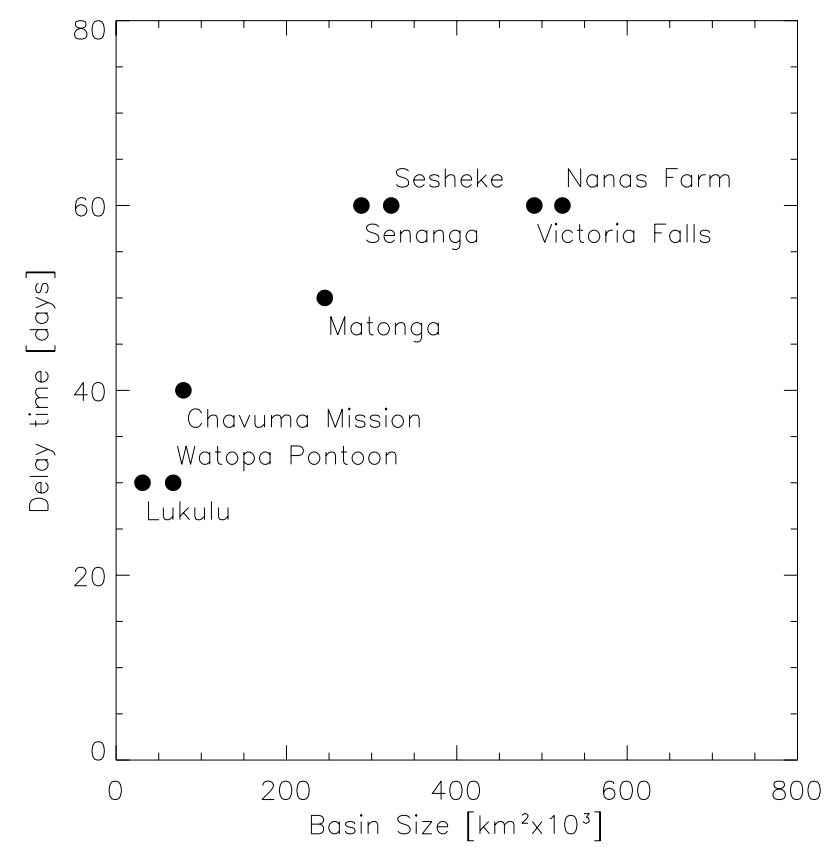

Fig. 6. Relation between basin-size and delay time of the discharge system.

mines the high correlations. To check if the $B W I$ is not only sensitive to annual variations, the coefficient of determination has been determined for the dry and rainy season independently and in a second step anomalies have been compared. To calculate the coefficients of determination for the dry season only measurements taken during the period July to October have been considered, for the rainy season only measurements taken during the period November to March. The resulting coefficients of determination are comparable to those calculated using all measurements. The values for the dry season are a bit lower than those from the wet season. This observation is not surprising, considering that the runoff behaviour of the Zambezi is more sensitive to differences between dry and wet years during the rainy season. During the dry season runoff is generally low with little differences between the years. In any case these results indicate that the model is robust and that it correctly reflects year to year differences during high and low flow seasons.

Anomalies were calculated by subtracting the mean annual cycle from the samples (both from the BWI and the hydrometric series). The mean annual cycle was calculated taking the mean at each decad over the years 1992-2000. If measurement series were incomplete, care was taken that the calculation of the mean hydrometric parameter and scatterometer soil moisture were based on the same data range. Mean values were only calculated if at least two measurements per sample interval were available, otherwise the respective sample was removed from the data set. Figures 7 and 8 show scatterplots of the anomalies. To ease interpretation both 

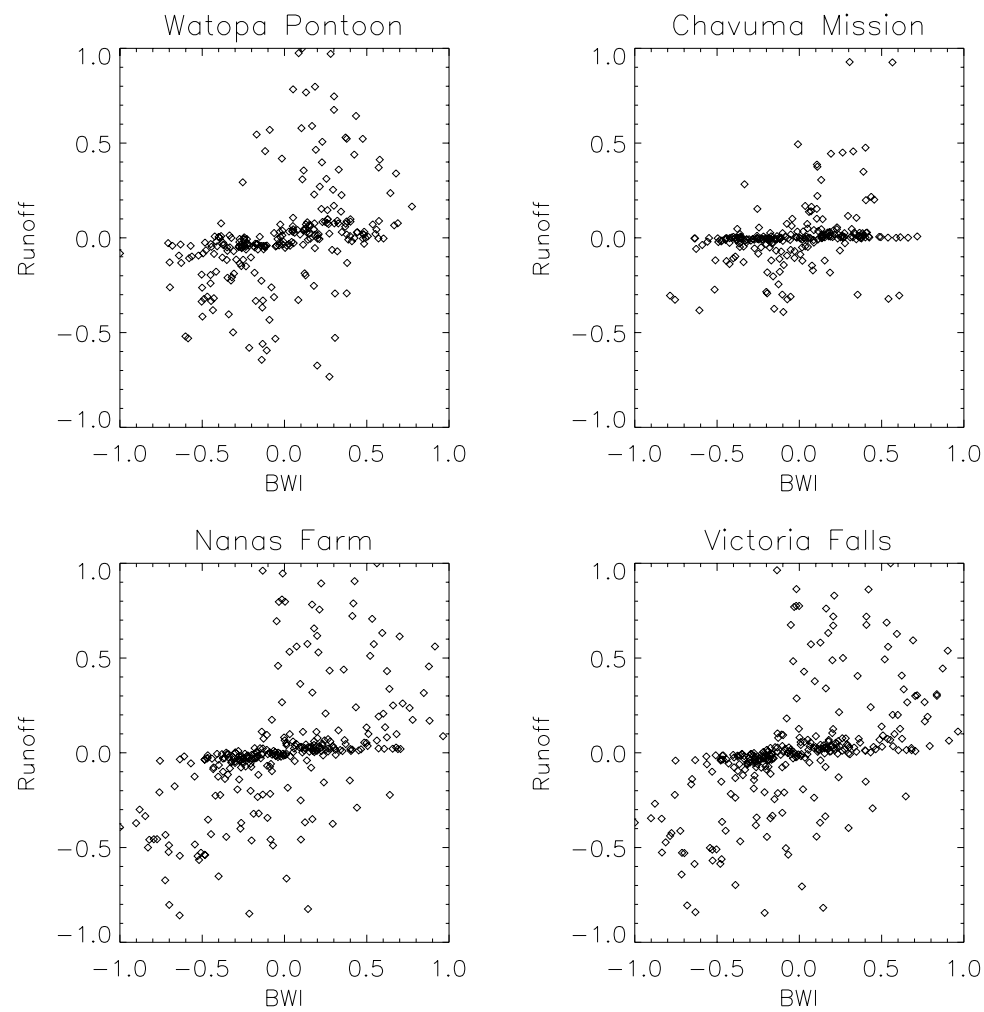

Fig. 7. Scatterplot of Basin Water Index and discharge anomalies at four gauging stations of the Zambezi River. Anomalies are scaled between -1 and +1 .
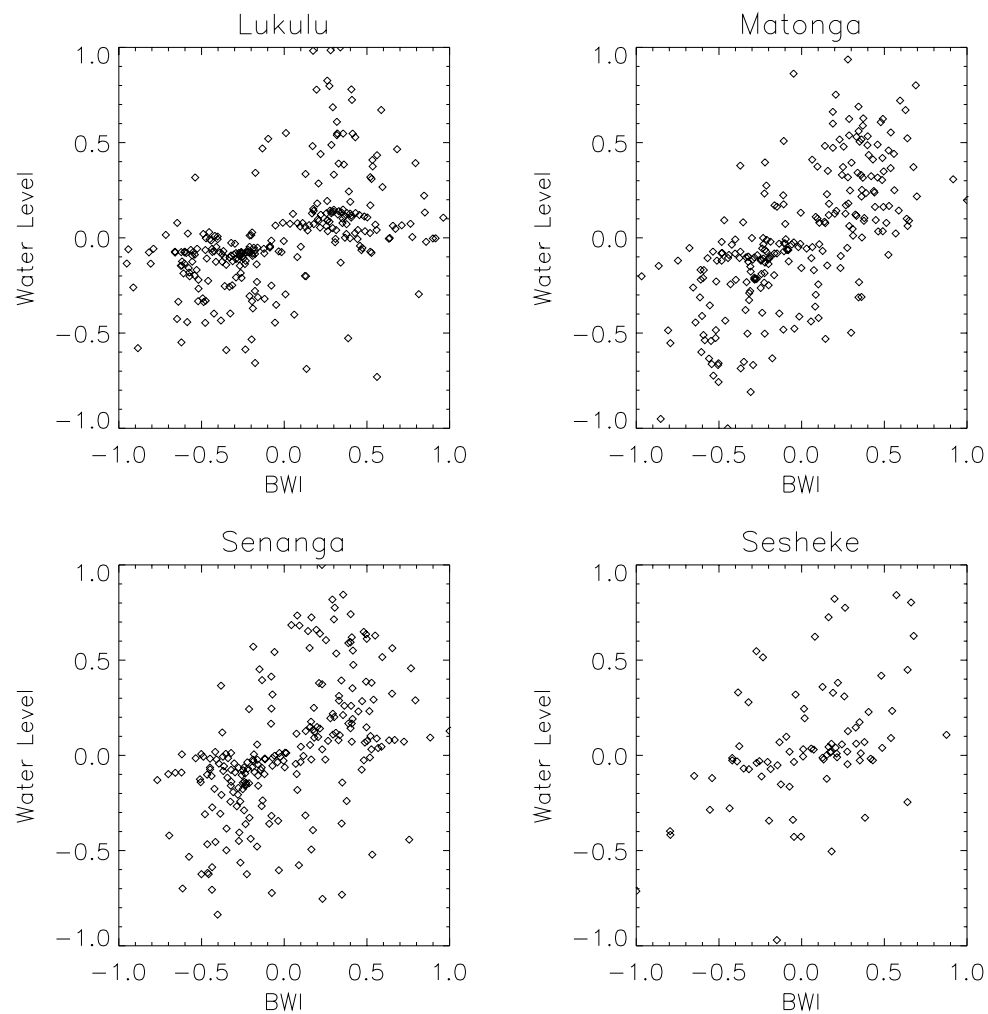

Fig. 8. Scatterplot of Basin Water Index and water level anomalies at four gauging stations of the Zambezi River. Anomalies are scaled between -1 and +1 . 
quantities have been scaled between -1 and +1 . The trend observed in all plots is positive which indicates that differences in runoff/waterlevel from year to year can to some extent be explained by soil moisture anomalies. However under dry conditions the $B W I$ anomalies show much more variability than the hydrometric anomalies. This is not surprising as especially under dry conditions variations caused by different precipitation/evapotranspiration rates only affect the soils. Given the lack of appropriate ground truth information about these quantities distinct conclusions are speculative and should be clarified in further studies.

\section{Conclusions}

In this paper a novel data set "The Global Soil Moisture Archive 1992-2000" has been presented. Although being not optimum for hydrologic applications due to the coarse resolution it was shown that the soil moisture products contain valuable information about large scale atmospheric induced variations of the soil moisture field. Contrary to the availability of this soil moisture data, a review of state of the art research led to the impression that concepts of how coarse resolution products can be used in hydrological modelling are still vague. The quality of the soil moisture data set, and first result of soil moisture assimilation studies however gave rise to the argument that coarse resolution soil moisture can successfully be used in hydrologic applications if scaling issues are considered carefully.

To assess the usefulness of coarse resolution soil moisture data for catchment scale modelling, scatterometer derived soil moisture data was compared to hydrometric measurements (runoff and water level) taken at eight gauging stations of the Zambezi River in Africa. For this purpose the "Basin Water Index" BWI has been introduced which integrates scatterometer derived soil moisture over the respective subbasins. Visual analysis showed a reasonable agreement between the $B W I$ and the hydrometric time series. Aside from a shift between the observed maxima of the two datasets climatic conditions and multi-annual variations are clearly visible. The observed shift could be explained with differences in the response time to precipitation events. To quantify results of the comparison between the BWI with hydrometric measurements a simple logarithmic regression model has been developed. Using this model considerable agreement was found, with coefficients of determination well above $R^{2}=0.8$. Also for anomalies a positive trend was observed which led to the feeling that differences in runoff/water level from year to year can to some extent be explained by soil moisture anomalies. However these results need to be considered carefully. It can be expected that the pronounced inter-annual cycle observed in the discharge behaviour of the Zambezi with a very dry period and a wet period predetermines the high correlations.
Nevertheless these observations are encouraging especially considering the approaching launch of a number of coarse resolution microwave sensors which will provide a flow of operational, global, high quality soil moisture data. Especially in ungauged basins these datasets might turn out as a valuable source of information to improve the predictive capability of runoff models, or just to use the data to improve and validate hydrologic process representation.

Acknowledgements. We would like to thank the Zambezi River Authority in Zambia for making hydrometric data available. The study has been funded by the Austrian Science Fund (FWF) through the GLOBSCAT project (L148-N10) and the Austrian Academy of Sciences through the HOE PUB project.

Edited by: G. Pegram

\section{References}

Aubert, D., Loumagne, C., and Oudin, L.: Sequential assimilation of soil moisture and streamflow data in a conceptual rainfallrunoff model, J. Hydrol., 280, 145-161, 2003.

Bach, H. and Mauser, W.: Methods and Examples for Remote Sensing Data Assimilation in Land Surface Process Modelling, IEEE Geosci., 41, 1629-1637, 2003.

Blöschl, G. and Sivapalan, M.: Scale issues in hydrological modelling: A Review, Hydrol. Proc., 9, 251-290, 1995.

Blöschl, G.: Scale and scaling in hydrology, Wiener Mitteilungen, Wasser Abwasser Gewässer, Band 132, Insitut für Hydraulik, Gewässerkunde und Wasserwirtschaft, Technische Universität Wien, 1996.

Cayan, D. R. and Georgakakos, K. P.: Hydroclimatology of continental watersheds: II spatial analyses, Water Res. R., 31, 677697, 1995.

Ceballos, A., Martinéz-Fernández, J., Santos, F., and Alonso, P.: Soil Water Behaviour of sandy soils under semi-arid conditions in the Duero Basin (Spain), J. Arid Env., 51, 501-519, 2002.

Ceballos, A., Scipal, K., Wagner, W., and Martínez-Fernández, J.: Validation of ERS Scatterometer-Derived Soil Moisture Data in the Central Part of the Duero Basin, Spain, Hydrol. Proc., 19, 1549-1566, 2005.

Crow, W. T. and Wood, E. F.: The assimilation of remotely sensed soil brightness temperature into a land surface model using Ensemble Kalman filtering: A case study based on ESTAR measurements during SGP97, Adv. Water R., 26, 137-149, 2002.

De Ridder, K.: Quantitative estimate of skin soil moisture with the Special Sensor Microwave/Imager, Bound-Lay. M., 96, 421432, 2000.

Engman, E. T. and Chauhan, N.: Status of microwave soil moisture measurements with remote sensing, Remot. Sen. E., 51, 189198, 1995.

Entekhabi, D., Asrar, G. R., Betts, A. K., Beven, K. J., Bras, R. L., Duffy, C. J., Dunne, T., Koster, R. D., Lettenmaier, D. P., McLaughlin, D. B., Shuttleworth, W. J., van Genuchten, M. T., Wei, M., and Wood E. F.: An Agenda for Land- Surface Hydrology Research and a call for the Second International Hydrological Decade, B. Am. Meteor., 80, 2043-2058, 1999.

Entin, J. K., Robock, A., Vinnikov, K. Y., Hollinger, S. E., Liu, S., and Namkhai A.: Temporal and spatial scales of observed soil 
moisture variations in the extratropics, J. Geophys. Res-A., 105, $11865-11877,2000$.

Francois, C., Quesney, A., and Ottle C.: Sequential assimilation of ERS-1 SAR data into a coupled land surface hydrological model using an extended Kalman filter, J. Hydromete., 4, 473487, 2003.

Grayson, R. B., Blöschl, G., Western, A., and McMahon, T. A.: Advances in the use of observed spatial patterns of catchment hydrological response, Adv. Water R., 25, 1313-1334, 2002.

Hollinger, S. E. and Isard, S. A.: A Soil Moisture Climatology of Illinois, J. Climate, 7, 822-833, 1994.

Houser, P. R., Shuttleworth, W. J., Famiglietti, J. S., Gupta, H. V., Syed, K. R., Goodrich, D. C.: Integration of soil moisture remote sensing and hydrologic modelling using data assimilation, Water Res. R., 34, 3405-3420, 1998.

Kerr, Y. H., Waldteufel, P., Wigneron, J.-P., Martuzzi, J.-M., Font, J., and Berger, M.: Soil moisture retrieval from space: The Soil Moisture and Ocean Salinity (SMOS) mission, IEEE Geosci, 39, 1729-1735, 2001.

Kontorschikov, V. I.: Statistical structure of the soil moisture in Ukraine, (in Russian), 1979.

Koster, R. D., Houser, P. R., Engman E. T., Kustas W. P.: Remote Sensing May Provide Unprecedented Hydrological Data, http: //www.agu.org/eos_elec/97035e.html, 1999.

$\mathrm{Li}, \mathrm{J}$. and Islam, S.: On the estimation of soil moisture profile and surface fluxes partitioning from sequential assimilation of surface layer soil moisture, J. Hydrol., 220, 86-103, 1999.

Martinéz-Fernández, J. and Ceballos A.: Temporal stability of Soil Moisture in a Large-Field Experiment in Spain, Soil Sci. So., 67 1647-1656, 2003.

Meshcherskaya, A. V., Boldyreva, N. A., and Shapaeva N. D.: District Average Plant available soil water storage and the depth of snow cover, statistical analysis and its usage (some examples), Gidrometeoizdat, Leningrad, USSR, 243, (in Russian), 1982.

Moran, M. S., Hymer, D. C., Qi, J., and Sano, E. E.: Soil Moisture Evaluation Using Multi-Temporal Synthetic Aperture Radar (SAR) in Semiarid Rangeland, Agr. For. Met., 105, 69-80, 2000.

Njoku, E.: AMSR-E/Aqua L2B Surface Soil Moisture, Ancillary Parms, \& QC EASE-Grids V001, March to June 2004. Boulder, CO, USA: National Snow and Ice Data Center, Digital media, 2004.

Pauwels, V. R. N., Hoeben, R., Verhoest, N. E. C., and DeTroch, F. P.: The importance of the spatial patterns of remotely sensed soil moisture in the improvement of discharge predictions for small scale basins through data assimilation, J. Hydrol., 251, 88-102, 2001

Reichle, R. H., Mc Laughlin, D. B., and Entekhabi, D.: Variational data assimilation of microwave radiobrightness observations for land surface hydrology applications, IEEE Geosci, 39, 17081718,2001
Robock, A., Vinnikov, K. Y., Srinivasan, G., Entin, J. K., Hollinger, S. E., Speranskaya, N. A., Liu, S., and Namkhai, A.: The Global Soil Moisture Data Bank, B. Am. Meteor., 81, 1281-1299, 2000.

Rombach, M. and Mauser, W.: Multi-annual analysis of ERS surface soil moisture measurements of different land uses, 3rd ERS Symposium on Space at the service of our Environment, Florence, Italy, 14-21 March, European Space Agency, SP-414, 27 34, 1997.

Scipal, K.: Global Soil Moisture Monitoring using ERS Scatterometer Data, Dissertation an der Technisch Naturwissenschaftlichen Fakultät, Technische Universität Wien, Juni, 2002.

Scipal, K., Wagner, W., Trommler, M., and Naumann, K.: The Global Soil Moisture Archive 1992-2000 from ERS Scatterometer Data: First Results, in: Proc. IGARRS'2002, Toronto, Canada, 24-28 June, 2002.

Vachaud, G., Passerat de Silans, A., Balabanis, P., and Vauclin M.: Temporal stability of spatially soil water probability density functions, Soil Sci. So., 45, 1040-1048, 1985.

Vieria, S. R., Nielsen, D. R., and Biggar J. W.: Spatial variability of field meassured infiltration rate, Soil Sci. So., 67, 1647-1656, 1981.

Vinnikov, K. Y., Robock, A., Qiu, S., Entin, J. K., Owe, M., Choudhsury, B. J., Hollinger, S. E., and Njoku, E. G.: Satellite remote sensing of soil moisture in Illinois, USA, J. Geophys. Res-A., 105, 4145-4168, 1999.

Wagner, W., Noll, J., Borgeaud M., and Rott, H.: Monitoring soil moisture over the Canadian Prairies with the ERS scatterometer, IEEE Geosci., 37a, 206-216, 1999a.

Wagner, W., Lemoine, G., Borgeaud, M., and Rott, H.: A study of vegetation cover effects on ERS scatterometer data, IEEE Geosci., 37b, 938-948, 1999b.

Wagner, W., Lemoine, G., and Rott, H.: A Method for Estimating Soil Moisture from ERS Scatterometer and Soil Data, Remot. Sen. E., 70, 191-207, 1999c.

Wagner, W., Scipal, K., Pathe, C., Gerten, D., Lucht, W., and Rudolf, B.: Evaluation of the agreement between the first global remotely sensed soil moisture data with model and precipitation data, J. Geophys. Res-A., 108, 4611-4626, 2003.

Walker, J. P. and Houser, P. R.: A methodology for initializing soil moisture in a global climate model: assimilation of near-surface soil moisture observations, J. Geophys. Res-A., 106, 11761$11774,2001$.

Walker, J. P., Willgoose, G. R., and Kalma, J. D.: One-dimensional soil moisture profile retrieval by assimilation of near-surface observations: A comparison of retrieval algorithms, Adv. Water R., 24, 631-650, 2001.

Zambezi River Authority: http://www.zaraho.org.zm, 2002. 